\title{
Does Teachers' Involvement Affect the Extent of School Bullying?
}

\author{
Mingyuan Chen ${ }^{1, \dagger}$, Shuang $\mathrm{Gao}^{2, \dagger}$, Yuqing $\mathrm{Jin}^{3, *, \dagger}$ \\ ${ }^{1}$ Wuhan University of Technology, Wuhan, Hubei, China \\ ${ }^{2}$ Jilin International Study University, Changchun, Jilin, China \\ ${ }^{3}$ Monash University, Melbourne, Victoria, Australia \\ *Corresponding author. Email: yjin0046@student.monash.edu \\ Those authors contributed equally.
}

\begin{abstract}
The topic of school bullying has been studied worldwide for many years, and previous research has shown that school bullying could be affected by many factors, including teachers' actions towards school bullying. However, to what extent would teacher's involvement affect school bullying remains unclear. In this study, the group is going to review some previous research papers. The hypothesis is that there is a negative relationship between teacher involvement and students' bullying, which is, with more teacher involvement, there would be less school bullying among students.
\end{abstract}

Keywords: students, school bullying, teacher's involvement, high school, teenagers.

\section{INTRODUCTION}

School bullying is recognized as a pervasive problem worldwide, which is studied by global research communities. The definition of bullying is critical for its academic and practical implications. Olweus's widely cited definition of bullying identified three prominent characteristics of bullying behavior: negative actions, repetition, and power imbalance [1]. Further study showed that the bullying conceptions were categorized into six major types: physical bullying, verbal bullying, relational bullying, property bullying, coercive behavior, and behavioral bullying [2]. According to the theory presented by Awiria and Rigby, persistent experiences of being bullied could cause great distress to victims, and a school climate in which bullying was permitted was likely to be damaging to social relationships generally $[3,4]$.

Additionally, based on Juvonen et al. [5], school bullying would affect students' physiological mechanisms, mental health and academic performance. Therefore, many individuals who suffer from bullying might have depression or anxiety disorders [6]. Sometimes school bullying could even lead to posttraumatic stress disorder or acute stress disorder. Many studies have shown that being bullied could lead to long-lasting influences, such as interpersonal violence, sexual violence, drug addiction, unsociable, or poor academic performance [6]. More seriously, even watching bullying behavior could negatively influence a person's well-being [6].

In conclusion, the victims showed negative results at the post-bullying stage, including mental and physical harm and damage to property and rights. On the one hand, syndromes of mental and physical harm included bodily harm, emotional distress, feeling overshadowed by psycho-violence, and losing self-confidence. On the other, damage of property and rights included the deprivation of one's rights, benefits, reputation, and possessions [2].

This study aims to find the relationship between the teacher's involvement and the extent of school bullying to help teachers learn more about how to make a difference in school bullying. A previous study showed that the teacher-student relationship could be an important factor affecting school bullying. Teachers' attitudes towards bullies often impact the development of campus bullying, and teachers' inappropriate intervention behavior would aggravate campus bullying [7]. For example, bullies could use the teacher's authority to bully the positional inferior because the bullying behavior involves power manipulation [2]. The study focuses on teachers' involvement because recent research has highlighted the issue of bullying in schools in China. However, little attention has been paid to the trained teachers, who will hold a key position in 
reducing the problem of bullying in schools [8]. And recent research showed that the educators might be more experienced in observing students' behavior and might have a better command of the language, and therefore they were able to notice what the other roles could not observe, however, teachers mentioned the situation of 'powerless to stop' [2]. Therefore, to reduce bullying, we will study the teacher's involvement in school bullying and help teachers learn more about how to reflect on school bullying. We intend to collect and sort out the results of previous researchers to find the answer.

\subsection{The influence of teachers' intervention on the degree of campus bullying}

Wallace (1994, as cited in 9) showed that teachers' behaviors about hope, joy, and respect effectively changed and improved students with bad behaviors. On the other hand, the teacher's negative behaviors, such as swearing, taking the students to the principal, or taking students out of the classroom, ignoring students' feelings, could negatively affect students' behavior [9]. Lacking discipline in school might lead to many troubles for children and teenagers, and it could become the root that causes failure. (Gary Arlow, 1999, as cited in 9). Crowley (1993, as cited in 9) showed that students were more likely to accept the teachers as friends or partners [9].

Similar to how teachers influence students' behavior, teachers play an important role in managing bullying in the classroom (Yoon and Bauman, 2014, as cited in 10). Therefore, understanding and training the teacher to predict the characteristics of responding to school bullying and victimization is the most important thing for preventing programs [10].

For implementation behaviors, teachers were more able to affect students' bullying reports via the teacher's intervening after bullying happened. It showed that the indirect influence was obvious [10]. Low levels of school bullying and victimization were connected to the teacher's job satisfaction, and it showed how professional achievement influenced the atmosphere in the classroom [10].

The research of Han, Zhang \& Zhang (2017) investigated the bullying behaviors of students in elementary, middle, high and technical schools in seven provinces in China. The self-evaluation relationship with teachers or classmates and GPA were asked via questionnaire forms, and the forms were managed via 5Point Likert Scales. The self-reported rate of victims was $26.10 \%$, bullying was $9.03 \%$, and witnessed bullying was $28.90 \%$. Elementary schools and top schools had a higher rate of bullying. It showed that the teacher-student relationship was one of the important protective factors for bullying behaviors [11]. It meant that the more teachers intervened, the fewer bullying accidents might happen.

In another research, researchers selected students from middle schools (i.e., the middle $33 \%$ of academic ratings) in Hong Kong [12]. A total of 1,480 students (grades 7-9) from four different schools in Hong Kong participated in the study from September 2004 to August 2006. Around $85 \%$ of the students were from 12-14 years old. The research used the 6 points Likert Scale, which questioned eight parts: levels of self-esteem, hurting others, lack of empathy, belonging, positive impression of teachers, school harmony, bullying, and caring [12].

According to Wong, Cheng, Ngan, Ma (2010), the results showed that several factors could be noticed from observing the implementation [12]. Firstly, school management was important, especially for the principal and the teacher. They were required to have cooperative behaviors. Secondly, it was important for the teacher and students to build a harmonious school together. A useful plan had to include professional training strategies for school teachers [12].

In Crothers, Kolbert, Barker's (2006) study, participants were middle school students from a small manufacturing city school district in the US. The races included Caucasian, African-American, American Indian/Alaskan Native, Hispanic, and Asian. The convenience sample included 285 students who had parental permission to participate in the study, and they represented $46 \%$ of 614 students in the middle school [13]. The variable was the intervention ways students would like educators to access when a bullying accident happens. The questionnaires included: the strategies kids may use, the ways teachers may use, and the strategies non-teaching staff may use. Students rated how helpful the strategies might be. The outcomes showed that the students believed the teacher's involvement was the most helpful in intervening in bullying situations. The two top-rated things were the methods that teachers would use, and the third top-rated thing was the method of teachers or non-teaching staff [13].

According to Pearce and Thompson, each occurrence of bullying behavior meant: the bullier did not realize that their behavior was unacceptable; the bullier was not taught to control their aggression; the victim might not be confident enough and not being protected; adult supervision failed [14].

These points above showed that the responsibility for bullying is not only focused solely on the bullier [14]. The teachers could play an important role in preventing bullying behavior. When a bullying accident happens, adults have to review all possible ways of preventing it and consider the reasons for bullying. Even though bullies are responsible for their actions, it is important that adults responsible for monitoring and teaching also have some responsibilities. So, teachers 
and parents have to work together to get supervision or training to prevent bullying from happening again [14].

\subsection{Case studies about teachers' intervention on the degree of campus bulling}

In addition, some case studies can directly or indirectly support the above views. The following are three typical cases.

Sun(2021) showed that teachers could aggravate the results of campus bullying to a certain extent. A 15 -yearold boy committed suicide by drinking pesticides in 2016 because he could not bear campus bullying. Before committing suicide, the boy tried to ask the headteacher for help, but the headteacher did not intervene in campus bullying. The teacher criticized and educated the victim, which indirectly caused an extremely bad social impact. This shows that if teachers do not intervene in campus bullying, it will further develop and worsen campus bullying [15].

According to $\mathrm{Xu}(2021)$, the bully can be affected by social workers through correct guidance. In this case, the researchers set up five intervention activities for the bully. The main objective was to develop the bully's empathy, behavior and emotion management skills. In this case, the researcher interacted with the perpetrators of campus bullying through interviews, role-playing, relaxation training and emotional simulation training, aversive therapy and alternative behavior reinforcement. After five interventions, the bully's violent behavior (including verbal violence and physical violence) on the campus decreased significantly. This case strongly supports the idea that with correct guidance, school bullying can decrease with teachers' involvement, though the case did not involve teachers [16].

Further, according to Zhou (2019), if teachers emphasize students' academic progress and lack moral education, students will lack moral consciousness and lead to campus bullying. This case also points out that the uneven ability of teachers is also one of the reasons why campus bullying is difficult to manage systematically. Very few teachers have problems with their morality. Therefore, they can neither set an example for students nor correctly guide students [17]

In conclusion, many case studies have shown that teachers play a significantly important role in school bullying, whether controlling school bullying or making school bullying worse.

\section{INFLUENCING FACTORS OF TEACHERS' INTERVEVTION IN CAMPUS BULLYING AND SOLUTIONS}

Teachers' responses to a bullying incident make an effect. The victims might perceive a teacher's passive actions with a perpetrator as unconcerned or unable to protect them [18]. Within this indulgent context, the victims might fear retaliation from the perpetrator if they 'tattle', so the victims would be less likely to report in the future that they are being bullied [19]. As a result of inconsistency in or lack of effective intervention, victims would remain silent and victimized. So, Teachers should intervene appropriately when they find bullying on campus.

The recent research showed that with better relations with teachers, the student would have a lower probability of reporting being bullied, being a perpetrator and witnessing bullying scenarios. And their analysis revealed that school climate, especially the relationship with teachers and peers, were significant protective factors in being bullied [11]. The protective effects of relation with teachers on bullying others and witnessing bullying were also significant [11]. Most of the prior studies support such conclusions crossculturally in Iceland [20], The Netherlands [21], the United States [22] and Hong Kong [23], Macau [24].

However, curbing bullying should not only rely on the good relationship between teachers and students. Even if teachers knew what bullying was and had information about what was going on in their classroom, they might still interpret it as playing or other innocent childhood behavior [25]. Previous studies investigated teachers' views on the prevalence of bullying by comparing teachers' and students' reports on bullying in the classroom. These studies found that these reports were very different from each other [26]. For instance, Craig, Henderson, and Murphy (2000) found that whereas teachers believed they were sufficiently aware of the bullying in their classroom, their students thought teachers were only aware of a fraction of all the bullying incidents [27].

Therefore, to make teachers fully aware of school bullying, how teachers define bullying is not a trivial issue. Yoon and Kerber's study investigated teachers' attitudes regarding three types of bullying: verbal, physical, and social exclusion [18]. This study shows that teachers view social exclusion less seriously and are less likely to intervene than verbal and physical aggression [18]. Furthermore, they also indicated that teachers were less sympathetic to the victim when addressing students' social exclusion and were less likely to get involved [18]. And according to recent studies, Children reported that teachers' attitudes toward children with disabilities often influenced the social exclusion experienced by peers [28]. So, the teacher must strengthen the comprehension of bullying.

Although it remains to be seen how an individual's conception of bullying may influence actual behavior, it would not be unreasonable to suggest that a teacher who does view a particular type of event as bullying may be more likely to intervene if she or he saw it take place, or respond more vigorously if it was reported to them, than 
another who does not view it as bullying [29]. Such an attitude-behavior link had been suggested for other types of pupils' misbehavior [30]. So, the covert nature of social exclusion warranted more systematic efforts at prevention [18]. Victims of direct and indirect bullying were often rejected and neglected by their peers [31]. Teachers also needed to be made aware of the behavioral patterns of the perpetrators and victims [18].

But observational data suggested that children were quite skilled at hiding this kind of social behavior from teachers [32]. In another word, The covert nature of social exclusion warranted more systematic efforts at prevention. Teachers needed to be made aware of the behavioral patterns of the perpetrators and victims. Victims of direct and indirect bullying are often rejected and neglected by their peers [31]. According to Bauman, S., Rigby, K., \& Hoppa, K.'s research, receiving extensive training in many skills essential to responding to bullying incidents contributed to the cognitive gap of bullying between different educators [33].

If nothing was done, the consequences of bullying seem to worsen in the long run [34]. The sooner the bullying was recognized and dealt with, the better the chances of preventing its escalation and ending it [34]. And the colleagues and managers whose actions were required in the intervention also suffer the impact of bullying and need support [34]. This could be given in the form of clear institutional 'zero tolerance for bullying' - policies and instructions on how and when to act [35-37]. According to the National Working Conditions Barometer of Trade Union of Education in Finland (2014), approximately half of Finnish universities had already written policies on how to act in the case of bullying or inappropriate behavior [38]; onefifth has already advised their workers on the prevention of workplace bullying. In the faculty studied here, the university's web pages contained brief guidelines to promote appropriate workplace behavior and instructions on how to solve and prevent problematic situations related to sexual harassment or (over)exercising of power, and name those people who should be contacted in the event of such behavior [38].

A key factor in preventing bullying and misconduct was participatory leadership and dialogue [39, 40]. Since victims who had experienced a high level of social support were less vulnerable and suffered fewer adverse health effects due to long-term harassment, it was also important to promote social support at work and home [41, 42]. Faculty members might need to be trained to work collaboratively in an academic condition because active listening or conflict resolution skills cannot be taken for granted, and informal support is easier to accept than third-party mediation [43-44]. Especially when bullying and misconduct have spread to the whole organization or the supervisor is the bully, third-party intervention may be required [45-47].
However, external consultants could also fail, especially if the organizational culture was not considered [47]. Emdad et al. (2013: 714-715) stress that since bystanders and the whole organization were involved in bullying, the intervention should also focus on the whole workplace system [48].

\section{CONCLUSION}

In conclusion, much evidence and previous studies had supported the idea that teachers are one of the most vital factors related to school bullying and can prevent school bullying from deteriorating. Both teachers' intervening and the school's ministration can be vital; studies and cases have shown that they could have an important impact on victims and bullies. Teachers' cognitive bias towards school bullying will affect their response to such behavior, and personal morality will also affect the degree of campus bullying. In order to create a better environment with less school bullying happening, it is a feasible way to train teachers and let them systematically learn about campus bullying.

\section{REFERENCES}

[1]Olweus, D. (1994). Bullying at school. In Aggressive behavior (pp. 97-130). Springer, Boston, MA.

[2]Cheng, Y. Y., Chen, L. M., Ho, H. C., \& Cheng, C. L. (2011). Definitions of school bullying in Taiwan: A comparison of multiple perspectives. School Psychology International, 32(3), 227-243.

[3]Awiria, O. (1994). Practical Strategies for Psychological Measurement (n.d).BC campus. British Journal of Educational Studies, 42(4), 403-406. doi:10.2307/3121681

[4]Rigby, K. (2007). Bullying in schools: And what to do about it. Aust Council for Ed Research. Retrieved from https://books.google.co.jp/books?hl=en\&lr=\&id=K EUeLn09668C\&oi=fnd\&pg=PR6\&dq=bullying + in + schools + and + what + to + do + about + it\&ots $=$ NoTGj Uyq3J\&sig=nilnaMfKYaCYOV4eW7rZCH9Q2eM $\# \mathrm{v}=$ onepage \&q=bullying\%20in $\% 20$ schools $\% 20$ an d $\% 20$ what $\% 20$ to $\% 20 \mathrm{do} \% 20$ about $\% 20$ it\&f $=$ false

[5]Juvonen, Jaana; Graham, Sandra (2014).Bullying in Schools: The Power of Bullies and the Plight of Victims.Annual Review of Psychology, 65 (1),159185.doi:10.1146/annurev-psych-010213-115030

[6]Warner, M (2021). The impact of bullying on mental health (2021). Department of Psychiatry and Behavioral Science. The University of Texas. Retrieved from https://med.uth.edu/psychiatry/2021/03/12/theimpact-of-bullying-on-mental-health/ 
[7]Sun, J. (2021). Research on the impact of campus bullying in China. Fujian Tribune, (06). Retrieved from $\mathrm{CNKI}$

[8]Nicolaides, S., Toda, Y., \& Smith, P. K. (2002). Knowledge and attitudes about school bullying in trainee teachers. British journal of educational psychology, 72(1), 105-118.

[9] Shahmohammadi, N (2014). Review on the Impact of Teachers' Behaviour on Students' Selfregulation. Procedia. Social and Behavioral science. ScienceDirect. ELSEVIER. Retrieved from

https://reader.elsevier.com/reader/sd/pii/S18770428 13053111?token=987AB3E12DA9E5461DAB70D 1B7DC0CD75D7DB8ED899839F4735E2AE1AC 82A1058404D8BAAED615D0B2AEEAEE28F4B 8E5\&originRegion $=$ us-east1\&originCreation $=20210903173947$

[10] Luca, D, L \& Nocentini, A \& Menesini, E (2019). The Teacher's Role in Preventing Bullying. Educational Psychology. frontiers in Psychology. Retrieved fromhttps://www.frontiersin.org/articles/10.3389/fp syg.2019.01830/full

[11] Han, Z \& Zhang, G \& Zhang, H (2017). School Bullying in Urban China: Prevalence and Correlation with School Climate. MDPI. Retrieved fromhttps://www.mdpi.com/16604601/14/10/1116/htm

[12] Wong, D \& Cheng, C \& Ngan, R \& Ma, S (2010). Program Effectiveness of a Restorative WholeSchool Approach for Tackling School Bullying in Hong Kong. International Journal of Offender Therapy and Comparative Criminology. SAGE journel. Retrieved from https://journals.sagepub.com/doi/abs/10.1177/0306 $624 \times 10374638$

[13]Crothers, L \& Kolbert, J \& Barker, W (2006). Middle School Students' Preferences for AntiBullying Interventions. School Psychology International. Sage journals. Retrieved from https://journals.sagepub.com/doi/abs/10.1177/0143 034306070435

[14] Pearce, J \& Thompson, A (n.d). Archives of Disease in Childhood. BMJ Journals. Retrieved fromhttps://adc.bmj.com/content/79/6/528.full

[15] Sun Xuanyang. Study on the Coping Mechanism of Campus Bullying Incident-- Taking Tao XX Incident of $\mathrm{W}$ Middle School in $\mathrm{H}$ county of $\mathrm{Q}$ Province as an Example. Retrieved from Doi:10.27778/d.cnki.gqhzy.2020.000206
[16] Xv Hongyu. Research on Key Technologies of Rapid Manufacturing Three Dimensional Micro/Nano Structures via. Doi: 10.27805/d.cnki.gccgy.2021.000702

[17] Zhou Yiyue. Study on Bullying of Middle School Students_- Taking Q middle school in H city as an example. Retrieved from : https://kns.cnki.net/kcms/detail/detail.aspx?dbcode $=\mathrm{CMFD} \&$ dbname $=\mathrm{CMFD} 201902 \&$ filename $=1019$ 142595.nh\&uniplatform $=$ NZKPT\&v $=$ DGd1BW31 AtvXBEh\%25mmd2FcUmzSrla9PjG\%25mmd2BE Fsq1SLTAII3SajGs4yphzcNigKyxSCdaFr

[18]Yoon, J. S., \& Kerber, K. (2003). Bullying: Elementary teachers' attitudes and intervention strategies. Research in Education, 69(1), 27-35.

[19]Pepler, D. J., Craig, W. M., Ziegler, S., and Charach, A. (1994), 'An evaluation of an anti-bullying intervention in Toronto schools', Canadian Journal of Community Mental Health 13, 95-110.

[20]Mann, M.J.; Kristjansson, A.L.; Sigfusdottir, I.D.; Smith, M.L. The role of community, family, peer, and school factors in group bullying: Implications for school-based intervention. J. Sch. Health 2015, $85,477-486$.

[21]Jansen, P.W.; Verlinden, M.; Berkel, A.D.; Mieloo, C.; van der Ende, J.; Veenstra, R.; Verhulst, F.C.; Jansen, W.; Tiemeier, H. Prevalence of bullying and victimization among children in early elementary school: Do family and school neighbourhood socioeconomic status matter? BMC Public Health 2012, 12, 494.

[22]Gower, A.L.; McMorris, B.J.; Eisenberg, M.E. School-level contextual predictors of bullying and harassment experiences among adolescents. Soc. Sci. Med. 2015, 147, 47-53.

[23] Chan, H.C.O.; Wong, D.S.W. The overlap between school bullying perpetration and victimization: Assessing the psychological, familial, and school factors of Chinese adolescents in Hong Kong. J. Child Fam. Stud. 2015, 24, 3224-3234.

[24] Chan, H.C.O.; Chui, W.H. Social bonds and school bullying: A study of Macanese male adolescents on bullying perpetration and peer victimization. Child Youth Care Forum 2013, 42, 599-616.

[25]Mishna, F., \& Alaggia, R. (2005). Weighing the risks: A child's decision to disclose peer victimization. Children and Schools, 27, 217-226. doi:10.1093/cs/27.4.217

[26]Oldenburg, B., Bosman, R., \& Veenstra, R. (2016). Are elementary school teachers prepared to tackle 
bullying? A pilot study. School Psychology International, 37(1), 64-72.

[27]Craig, W. M., Pepler, D., \& Atlas, R. (2000). Observations of bullying in the playground and in the classroom. School Psychology International, 21, 22-36. doi:10.1177/0143034300211002.

[28]Lindsay, S., \& McPherson, A. C. (2012). Experiences of social exclusion and bullying at school among children and youth with cerebral palsy. Disability and rehabilitation, 34(2), 101-109.

[29]Boulton, M. J. (1997). Teachers' views on bullying: Definitions, attitudes and ability to cope. British Journal of Educational Psychology, 67(2), 223-233.

[30]Chazan, M., Harper, G. C., \& Laing, A. F. (1987). Teaching five to eight year olds. Basil Blackwell.

[31]Bigbee, M. A., and Grotpeter, J. K. (1995), 'Relational and overt forms of victimisation and aggression', poster presented at the meeting of the Society for Research and Child Development, Indianapolis IN, April.

[32]Craig, W. M., Pepler, D., and Atlas, R. (2000), 'Observations of bullying in the playground and in the classroom', School Psychology International $21,22-36$.

[33]Bauman, S., Rigby, K., \& Hoppa, K. (2008). US teachers' and school counsellors' strategies for handling school bullying incidents. Educational Psychology, 28(7), 837-856.

[34]Meriläinen, M., Sinkkonen, H. M., Puhakka, H., \& Käyhkö, K. (2016). Bullying and inappropriate behaviour among faculty personnel. Policy Futures in Education, 14(6), 617-634.

[35]Bloch C (2012) How witnesses contribute to bullying in the workplace. In: Tehrani $\mathrm{N}$ (ed.) Workplace Bullying. Symptoms and Solutions. London: Routledge, pp.81-96.

[36]Cortina LM (2008) Unseen justice: Incivility as modern discrimination in organizations. Academy of Management Review 33: 55-75.

[37]Zabrodska K, Ellwood C, Zaeemdar S, et al. (2014) Workplace bullying as sensemaking: An analysis of target and actor perspectives on initial hostile interactions. Culture and Organization 22(2): 136157.
[38]Meriläinen, M., Sinkkonen, H. M., Puhakka, H., \& Käyhkö, K. (2016). Bullying and inappropriate behaviour among faculty personnel. Policy Futures in Education, 14(6), 617-634.

[39]Hoel H, Glasø L, Hetland J, et al. (2010) Leadership styles as predictors of self-reported and observed workplace bullying. British Journal of Management 21: 453-468.

[40]Mikkelsen EG, Hogh A and Puggaard LB (2011) Prevention of bullying and conflicts at work: Process factors influencing the implementation and effects of interventions. International Journal of Workplace Health Management 4(1): 84-100.

[41]Einarsen S (2000) Harassment and bullying at work: A review of the Scandinavian approach. Aggression and Violent Behavior 5: 379-401.

[42]Twale DJ and De Luca BM (2008) Faculty Incivility: The rise of the academic bully culture and what to do about it, 1st. San Francisco, CA: John Wiley \& Sons.

[43]Keashly L and Neuman JH (2010) Faculty experiences with bullying in higher education. Causes, consequences, and management. Administrative Theory \& Praxis 32(1): 58-70.

[44]McKay R, Huberman AD, Fratzl J, et al. (2008) Workplace bullying in academia: A Canadian study. Employee Responsibilities and Rights Journal 20: $77-100$.

[45]Bartlett JE and Bartlett ME (2011) Workplace bullying: An integrative literature review. Advances in Developing Human Resources 13(1): 69-84.

[46]Namie G and Namie R (2009) The Bully at Work. What you can do to stop the hurt and reclaim your dignity on the job, 2nd. Naperville, IL: Sourcebooks.

[47]Vartia $M$ and Tehrani N (2012) Addressing bullying in the workplace. In: Tehrani $\mathrm{N}$ (ed.) Workplace Bullying. Symptoms and Solutions. London: Routledge.

[48]Emdad R, Alipour A, Hagberg J, et al. (2013) The impact of bystanding to workplace bullying on symptoms of depression among women and men in industry in Sweden: An empirical and theoretical longitudinal study. International Archives of Occupational and Environmental Health 86: 709716. 